\title{
Adhesion enhancement for liquid silicone rubber and different surface by organosilane and Pt catalyst at room temperature
}

\author{
FANG WANG*, YANNI LI and DAN WANG \\ College of Science, Northwest A\&F University, Xinong Road No. 22, Yangling, Shaanxi 712 100, China
}

MS received 5 May 2012; revised 29 September 2012

\begin{abstract}
Surface modification of aluminum, glass, epoxy resin, polypropylene and polyethylene via corona discharge pretreatment and platinum catalyst addition to promote their adhesion with liquid silicone rubber is reported. The corona-pretreated substrate surface was silanized with vinyltrimethoxysilane to generate vinyl groups on the surface, which could be initiated by platinum catalyst to form vinyl radicals. Then, the vinyltrimethoxysilane modified substrate was dipped into platinum catalyst solution to introduce platinum on the vinyltrimethoxysilane surface. The modified aluminum surface was characterized by X-ray photoelectron spectroscopy (XPS). The strong adhesion property between liquid silicone rubber and different surface was achieved by introducing a small amount of vinyltrimethoxysilane and platinum catalyst, followed by curing at low temperature. XPS result indicated the formation of vinyltrimethoxysilane coating on aluminum surface. Peel strength for liquid silicone rubber/vinyltrimethoxysilane-platinum surface was over $3.2 \mathrm{kN} / \mathrm{m}$ compared to only $1.1 \mathrm{kN} / \mathrm{m}$ for liquid silicone rubber/vinyltrimethoxysilane-aluminum. The cohesive failure in the bulk of liquid silicone rubber was observed for liquid silicone rubber/vinyltrimethoxysilane-platinum surface. It is assumed that the cross-linking reactions between vinyl groups in the vinyltrimethoxysilane coating and unsaturated terminal group of liquid silicone rubber occur due to the existence of platinum catalyst.
\end{abstract}

Keywords. Adhesion property; platinum catalyst; liquid silicone rubber; vinyltrimethoxysilane.

\section{Introduction}

Liquid silicone rubber (LSR) has been widely used to manufacture LSR materials (Zhou et al 2009; Ikeno et al 2010), which have been applied in many fields for more than twenty years, such as inner insulating material in pre-fabricated accessories of power cables (Hanley et al 2003), elastomeric housing materials of composite insulators in housings (Seifert et al 2007) and physical foaming in the injection moulding process (Ren et al 2008). LSR possesses a wide applicable temperature range, excellent resistance to chemicals, as well as to weathering and can readily adhere to all kinds of surfaces (Yamazaki 2006). The adhesion property between liquid silicone rubber and different surface plays a very significant role in application and affects performance of LSR materials. However, its adhesion strength is lower than that of organic rubbers because of the weaker interaction between polysiloxane macromolecules and other surfaces (Bokobza 2004). Considerable researches have been carried out to improve the

*Author for correspondence (wangfang4070@ nwsuaf.edu.cn; wf4070@yahoo.com.cn) adhesion property of LSR and surfaces (Wang et al 2006; Rios et al 2007; Roth et al 2008; Chen et al 2010). On the one hand, chemical modifications of LSR molecular structure have been attempted, such as replacing some of the methyl groups of poly(dimethylsiloxane) with vinyl groups, using vinyl-terminated methylvinylpolysiloxane as gum or adding methylene or phenylene to the main chain (Wang et al 2006; Gupta et al 2011a, b). Also, specific catalysts are introduced sometimes. On the other hand, surface treatment techniques have been attempted such as chemical treatment, light treatment and plasma treatment (Wang et al 2009). Main aim of the surface treatment is to introduce reaction functional groups to enhance the adhesion strength (Arroyo et al 2003).

In this paper, we demonstrated a method of improving adhesion strength between LSR and substrate. Corona discharge technique was applied to introduce hydroxyl functional groups on different substrate surfaces (aluminum, glass, epoxy resin, polypropylene and polyethylene), which reacted with another hydroxyl group from hydrolyzed vinyltrimethoxysilane (VMS). Subsequently, platinum catalyst (chloroplatinic acid hexahydrate, $\mathrm{H}_{2} \mathrm{PtCl}_{6} \cdot 6 \mathrm{H}_{2} \mathrm{O}$ ) was applied to be introduced into VMS treated surfaces. Then LSR was coated on them to investigate adhesion property by T-peel test. The whole process is shown in figure 1 . 


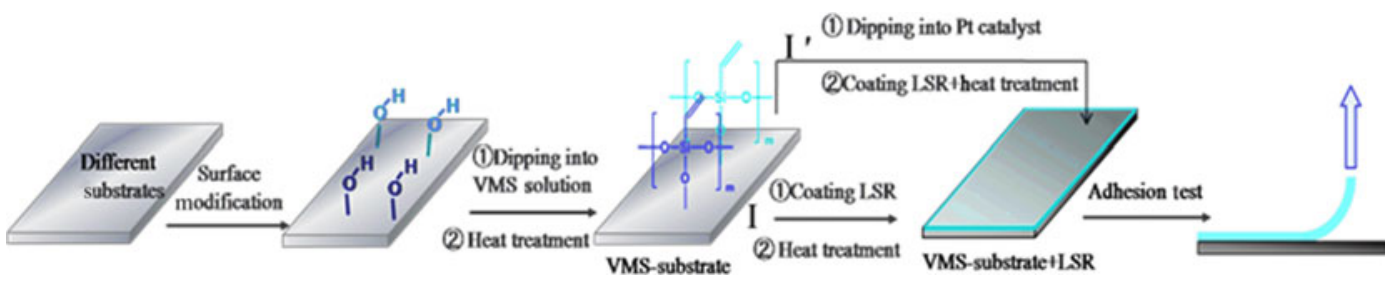

Figure 1. Model illustration of surface modification on substrate surface.

\section{Experimental}

\subsection{Material and reagents}

Aluminum (purity not less than 99.9995\%), glass, epoxy resin, polypropylene (PP) and polyethylene (PE) were prepared by cutting a large plate into pieces with the dimension of $30 \times 50 \times 1 \mathrm{~mm}$. All the test plates were cleaned by ultrasonic in acetone or ethanol for $15 \mathrm{~min}$, followed by ultrasonic washing in distilled water for $15 \mathrm{~min}$ and dried in nitrogen air. Then they were pretreated by corona discharge in atmospheric environment. Vinyltrimethoxysilane (VMS, 97\%) and liquid silicone rubber (LSR) were purchased from Sigma-Aldrich. VMS solution consisted of ethanol, distilled water and vinyltrimethoxysilane $(90 / 5 / 5$, $\mathrm{v} / \mathrm{v} / \mathrm{v})$.

\subsection{Surface preparation}

Before coating treatment, VMS solutions were kept under stirring at $30{ }^{\circ} \mathrm{C}$ for $24 \mathrm{~h}$ to allow the hydrolysis of $\mathrm{Si}-$ $\mathrm{OCH}_{3}$ groups. Then the pretreated different substrates were immersed in the hydrolyzed silane hydroalcoholic solution for $5 \mathrm{~min}$ at room temperature, rinsed by alcohol and dried with hot air flux. Successively, they were subjected to be cured at $150{ }^{\circ} \mathrm{C}$ in air oven for $10 \mathrm{~min}$ except that polypropylene (PP) and polyethylene (PE) were cured at 100 and $80^{\circ} \mathrm{C}$ for the same time, respectively.

Then the experiment was separated to reference experiment $(l)$ and $\mathrm{Pt}$ catalyst one $\left(l^{\prime}\right)$. The concentrations of $\mathrm{Pt}$ catalyst were controlled to 20, 60, 100 and 200 ppm, respectively. After LSR and LSR+Pt coating, the surfaces were cured. Finally, T-peel test was carried out to evaluate the adhesion property.

\subsection{Measurements}

X-ray photoelectron spectroscopy (XPS) was performed to determine the elemental composition of aluminum surface. Spectra were obtained using ULVAC PHI-5600 spectrometer equipped with monochrome $\mathrm{AlK} \alpha$ radiation $(1486.6 \mathrm{eV})$. The pressure in the preparation chamber was less than $10^{-7}$ Torr and less than $4 \times 10^{-10}$ Torr in the analysis chamber. Samples were examined over an area of $800 \times 2000 \mu \mathrm{m}$ and photoelectron spectra were recorded with a take-off angle of $45^{\circ}$. The peel strength of LSR and

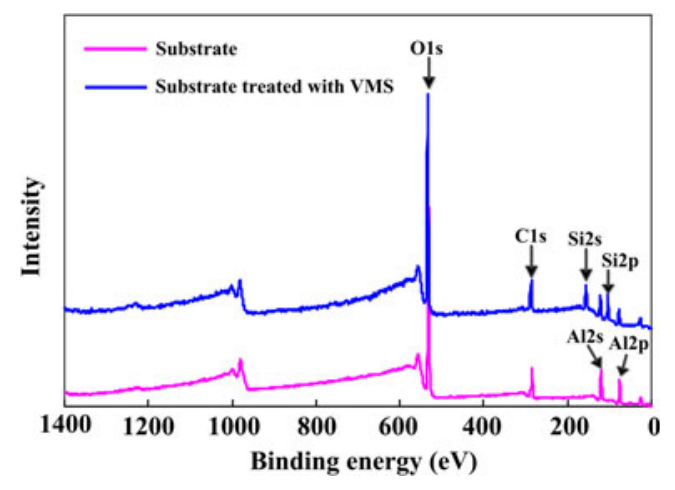

Figure 2. XPS spectra of untreated and VMS-treated aluminum surfaces in $45^{\circ}$ tilt degree (X-ray anode: Al monochromated $2 \mathrm{~nm}$ filament; aperture: $800 \times 2000 \mu \mathrm{m})$.

LSR + Pt coating on different substrates were investigated by T-peel test using autograph S-100 apparatus (Shimadzu Corporation).

\section{Results and discussion}

\subsection{Surface analysis by XPS spectra}

XPS spectra were investigated to confirm the formation of VMS coating on aluminum surface compared to the blank aluminum. It is seen that only peaks of Al $2 p(73.7 \mathrm{eV})$ and Al2s (119.6 eV) are observed (figure 2), except for the peaks of $\mathrm{C} 1 s(285.0 \mathrm{eV})$ and $\mathrm{O} 1 s(532.0 \mathrm{eV})$ for the untreated aluminum surface. However, the peaks of $\mathrm{Si} 2 p(101.9 \mathrm{eV})$ and $\mathrm{Si} 2 s(151.8 \mathrm{eV})$ corresponding to the VMS treated aluminum are detected. These results confirmed the formation of VMS coating on the aluminum surface. The atomic concentration for the relevant elements are summarized in table 1 .

In the case of VMS treatment, there were increased amounts of $\mathrm{C}(\mathrm{C} 1 s)$ and $\mathrm{Si}(\mathrm{Si} 2 s, \mathrm{Si} 2 p)$ and decreased amounts of $\mathrm{O}(\mathrm{O} 1 s)$ and $\mathrm{Al}(\mathrm{Al} 2 p, \mathrm{Al} 2 s)$ on the aluminum surface. The relevant element ranged from $0 \%$ for pure aluminum surface to about $10.76 \%$ (Si) and $22.07 \%(\mathrm{C})$ after modification. From the result, it can be concluded that $\mathrm{Si}-\mathrm{OH}$ groups of hydrolyzed VMS react with the hydroxyl group on the pretreated aluminum surface. The results also confirmed the formation of VMS coating on aluminum surface. 
Table 1. Atomic concentrations of VMS-treated and non-treated aluminum surface.

\begin{tabular}{lcccc}
\hline Elements & $\mathrm{C}(\%)$ & $\mathrm{O}(\%)$ & $\mathrm{Si}(\%)$ & $\mathrm{Al}(\%)$ \\
\hline Blank Al & 19.10 & 60.50 & - & 19.75 \\
$\mathrm{Al}+\mathrm{VMS}$ & 22.07 & 49.27 & 10.76 & 17.90 \\
\hline
\end{tabular}

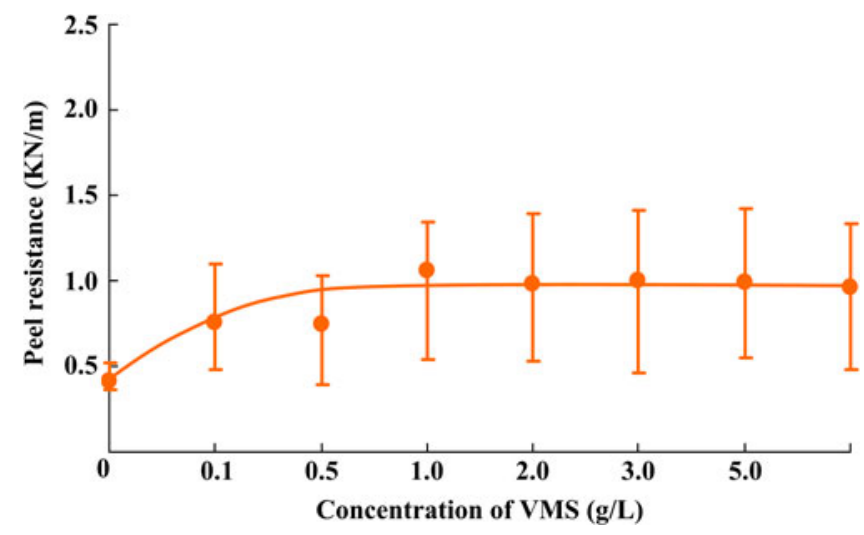

Figure 3. Effect of VMS concentration on peel strength between LSR and aluminum substrate.

\subsection{T-peel test}

The effect of VMS coating and Pt catalyst on the peel strength between LSR and aluminum substrate was discussed from the aspects of VMS and Pt catalyst concentration (Wang et al 2009). The peel strength was calculated according to the formula given below:

Peel strength $=F / L$,

where $F$ represents the peeling strength while peeling off the LSR from aluminum for the length of $L$. Figure 3 shows effect of VMS concentration on the peel strength in direct joining of LSR with VMS-treated aluminum. Undoubtedly, the aluminum substrate without VMS coating could not join to LSR and its fractured surface was at interface. Peel strength was measured for VMS concentration ranging from 0 to $6.0 \mathrm{~g} / \mathrm{L}$. For VMS concentration below $0.5 \mathrm{~g} / \mathrm{L}$, it could be seen that the peel strength was very low and the peel strength grew steadily to $1.1 \mathrm{kN} / \mathrm{m}$, when VMS concentration increases to $6.0 \mathrm{~g} / \mathrm{L}$. The fact that the peel strength was weak at low VMS concentration was probably due to the lower coverage and cross-linking degree.

The effect of Pt catalyst concentration on the peel strength in direct joining of LSR to aluminum substrate was shown in figure 4 . The dipping time in hydrolyzed VMS solution was $5 \mathrm{~min}$. The concentration of Pt catalyst had a significant influence on joining property of LSR with Al-VMS. The peel strength of adherence significantly increased with the concentration ranging from 0 to $20 \mathrm{ppm}$. With the increased in $\mathrm{Pt}$

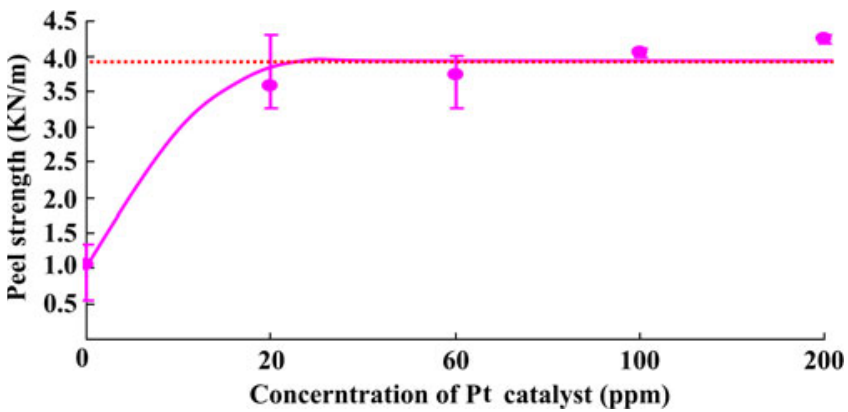

Figure 4. Effect of Pt concentration on peel strength between LSR and aluminum substrate.

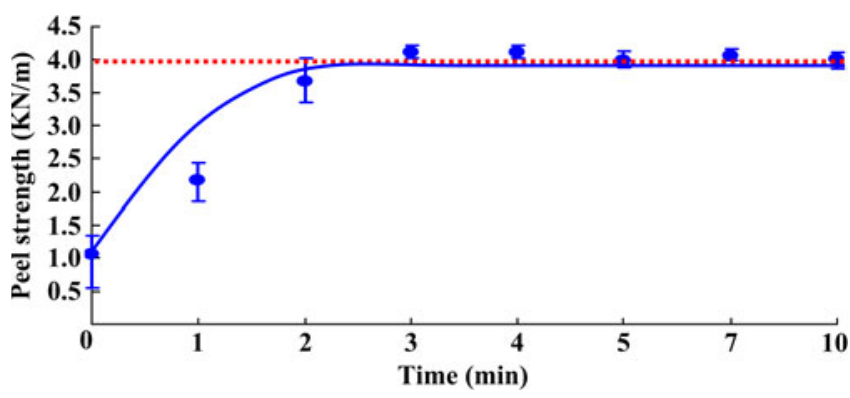

Figure 5. Effect of dipping time on peel strength between LSR and aluminum substrate.

concentration, it was proposed that the vinyl groups in VMS coating and unsaturated terminal group of LSR were initiated to result in the formation of more radicals and these radicals reacted with each other to generate cross-linking structure at LSR/VMS-Pt surface interface. The cross-linking structure made the peel strength become large. As the concentration was over $20 \mathrm{ppm}$, the peel strength increased gently and it was up to $4.0 \mathrm{kN} / \mathrm{m}$, till the Pt catalyst concentration was $100 \mathrm{ppm}$.

Figure 5 showed effect of VMS dipping time on the peel strength in direct joining of LSR with Al-VMS-Pt and the concentration of $\mathrm{Pt}$ catalyst was $100 \mathrm{ppm}$. The peel strength of adherends significantly increased with the dipping time ranging from 1 to $3 \mathrm{~min}$. When the dipping time was over $3 \mathrm{~min}$, the peel strength became invariable as dipping time increased. The peel strength of adherend reached to $4.1 \mathrm{kN} / \mathrm{m}$. The fact that peel strength was strong under long VMS dipping time was probably due to the higher coverage on aluminum surface and higher cross-linking degree caused by Pt catalyst.

Consequently, in order to obtain good adherend of LSR/Al with higher peel strength, the aluminum should be pretreated by corona discharge, followed by dipping into VMS and Pt catalyst solution. The concentrations and dipping times of VMS are $5.0 \mathrm{~g} / \mathrm{L}$ and $5 \mathrm{~min}$, and of Pt catalyst are $100 \mathrm{ppm}$ and $3 \mathrm{~min}$, respectively. 

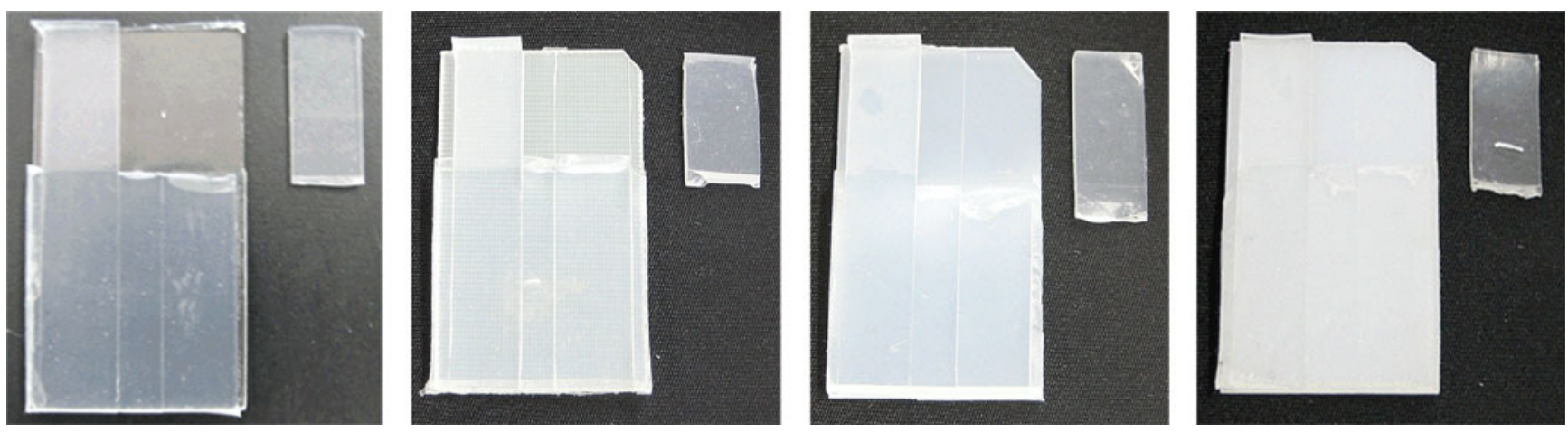

Figure 6. Peel strength between LSR and glass $(3.7 \mathrm{kN} / \mathrm{m})$, epoxy resin $(3.8 \mathrm{kN} / \mathrm{m})$, polypropylene $(3.2 \mathrm{kN} / \mathrm{m})$ and polyethylene $(3 \cdot 3 \mathrm{kN} / \mathrm{m})$.

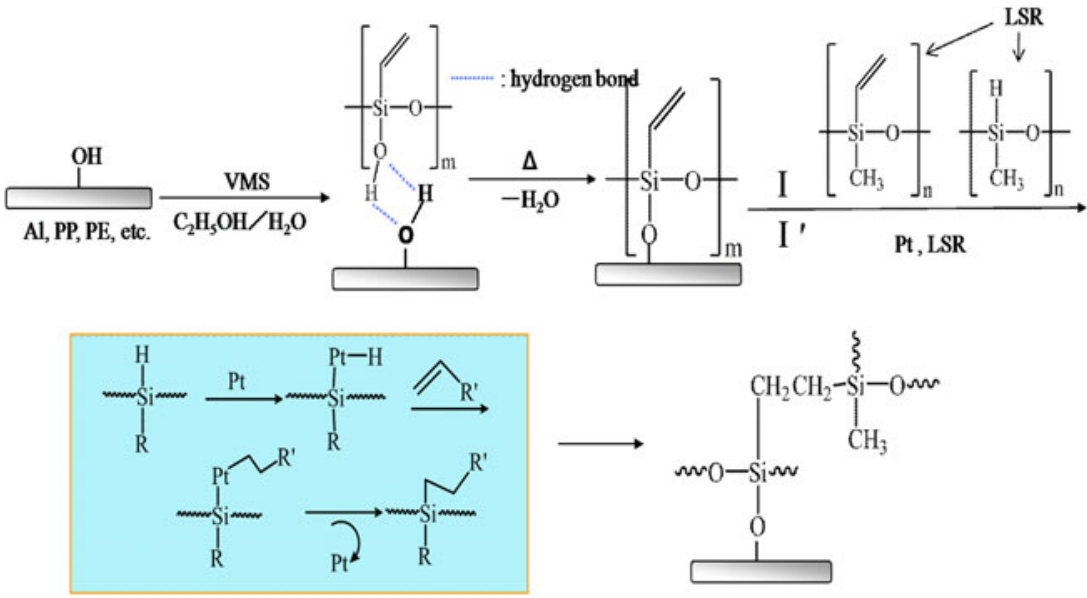

Figure 7. Schematic illustration of processes of VMS treatment, curing, Pt catalysis and simultaneous cross-linking reaction.

The peel strength between LSR and glass, epoxy resin, polypropylene (PP), polyethylene (PE) was investigated under the condition of $5.0 \mathrm{~g} / \mathrm{L}$ VMS, 5 min dipping time and $100 \mathrm{ppm}$ Pt catalyst, and the images are shown in figure 6. The peel strength was enhanced greatly compared with nonPt catalyzed surfaces. The peel strength with these substrates depended on the amount of hydroxyl groups on different surfaces after corona discharge modification. In other words, the atomic concentrations for oxygen element of different substrate surfaces significantly affected peel strength in addition to VMS and Pt catalyst.

\subsection{Mechanism analysis}

The formation mechanism for the adherends of LSR/VMSPt surface with strong peel strength was analysed (figure 7). The corona discharge pretreated surface was first silanized with vinyltrimethoxysilane (VMS) to form the interface with hydrogen bonding and generate the vinyl groups on substrate surface simultaneously, which could be initiated by Pt cata- lyst to form vinyl radicals (Brunner 2004). VMS modified surface was cured to generate Al-O-Si covalent bond on the substrate. Then the substrate was dipped into Pt-catalyst hexane solution to introduce Pt on the VMS surface. Finally, LSR was paved on VMS-Pt surface, followed by vulcanization at low temperature. It was assumed that vinyl groups in VMS coating and unsaturated terminal group of LSR were initiated to form the corresponding radicals and these radicals reacted with each other. At the same time, the crosslinking reaction of LSR occurred by means of Pt catalyst. As a result, the cross-linking structure was generated at LSR/VMS-Pt surface interface, which was able to realize the strong adhesion for LSR/VMS-Pt surface.

\section{Conclusions}

Surface modification and catalyst addition technique can greatly enhance the adhesion property between LSR and surfaces such as glass, epoxy resin, polypropylene and polyethylene with the peel strength ranging from $3 \cdot 2$ to $4 \cdot 1 \mathrm{kN} / \mathrm{m}$. 
The optimal concentrations and dipping times of VMS are $5.0 \mathrm{~g} / \mathrm{L}$ and $5 \mathrm{~min}$ and of Pt catalyst are $100 \mathrm{ppm}$ and $3 \mathrm{~min}$, respectively.

\section{Acknowledgements}

The authors express their sincere gratitude for Scientific Research Foundation for the Returned Overseas Chinese Scholars, State Education Ministry No. K314020902 and Fundamental Research Funds for the Central Universities No. Z109021008.

\section{References}

Arroyo M, López-Manchado M A and Herrero B 2003 Polymer 44 2447

Bokobza L 2004 J. Appl. Polym. Sci. 932095

Brunner H 2004 Angew. Chem. Int. Edit. 432749

Chen J, Wu W, You Y, Fan W and Chen Y J 2010 J. Appl. Polym. Sci. 1172964
Gupta S, Ramamurthy P C and Madras G 2011a Polym. Chem. 22643

Gupta S, Ramamurthy P C and Madras G 2011b Polym. Chem. 2221

Hanley L H, Burford R P, Fleming R J and Barber K 2003 IEEE Electr. Insul. M 1913

Ikeno M, Nakamura T, Mizushima H, Ubukata S, Todoroki D and Tanaka T 2010 US Patents No. 7,662,479 B2

Ren S W, Kochanek W, Bolz H, Wittmar M H, Grobelsek I M and Veith M 2008 J. Eur. Ceram. Soc. 283005

Rios P, Dodiuk H, Kenig S, McCarthy S and Dotan A 2007 J. Adhes. Sci. Technol. 213227

Roth J et al 2008 Langmuir 2412603

Seifert J M, Winter H J, Barsch R and Bognar A 2007 Electr. Insul. Dielectric Phenomena 329

Wang F, Xu J, Luo H Y, Wang J G and Wang Q 2009 Molecules 144087

Wang J C, Chen Y H and Jin Q Q 2006 J. Adhes. Sci. Technol. 202 261

Yamazaki T 2006 J. Soc. Rubber Ind. 79388

Zhou Y X, Wang J Y, Chen H H, Nie Q, Sun Q H and Wang Y S 2009 J. Electrostat. 67422 